\section{Evaluation of Weight Uniformity of Splitted Tablet}

\author{
*Md. Hassan Kawsar ${ }^{1}$, Md. Zia Uddin ${ }^{2}$, Aninda Kumar Nath ${ }^{2}$ \\ and Mycal Dutta ${ }^{2}$ \\ ${ }^{1}$ Department of Pharmacy, Dhaka International University \\ Dhaka, Bangladesh. \\ ${ }^{2}$ Department of Pharmacy, BGC Trust University \\ Chittagong, Bangladesh.
}

${ }^{*}$ Corresponding Author

Md. Hassan Kawsar

Associate Professor

Department of Pharmacy

Dhaka International University

Banani, Dhaka, Bangladesh.

Contact no.: +88 01554333537

E-mail: hassankawsar@yahoo.com

Received - 18 October 2010

Accepted for Publication - 21 November 2010

\begin{abstract}
Tablet-splitting is a widespread practice among all sectors of health care for different reasons: it increases dose flexibility, makes tablet parts easier to swallow and allows cost savings for both patients and healthcare providers. However, the tablet parts obtained are often not equal in size, and a substantial amount of tablet can be lost during splitting. This paper is a report of a study conducted to quantify the mean deviation from theoretical weight and the mean weight loss, of three different tablet preparations commonly used to manage hypertension. The tablets were Verapamil Hydrochloride $80 \mathrm{mg}$, Metoprolol Tartrate $50 \mathrm{mg}$ and Atenolol 50mg. A volunteer was used in the study to split 30 randomly selected tablet of each of the preparation using two different routine methods; manual splitting and with a kitchen knife. Before and after splitting, tablets and tablet parts were weighed using an analytical balance. All the methods showed significant deviation of weight than the theoretical. Large dose deviations or weight losses can occur while splitting tablets which could have serious clinical consequences for medications with a narrow therapeutic-toxic range. On the basis of the results in this report, we recommend use of a splitting device when splitting cannot be avoided.
\end{abstract}

Key words: Tablet-splitting, Weight deviations, Therapeutic-toxic range.

\title{
INTRODUCTION
}

Tablet splitting has become increasingly common especially within the generic and psychiatric communities, as a means of reducing medication dose and/or cost. Physicians frequently write prescriptions for half-tablet in order to achieve doses less than the smallest available manufactured strength. Prescribers also write for half and quarter-tablets. Dose adjustment is important in case of some patients. Some patients need full dose initially and need half dose latterly depending on the condition of disease. Sometimes physician prescribe half tablet because of inavailability of smaller dose or depending on extent of disease. (Fischbach et al., 2001; Biron et al., 1999; Van et al., 2002; Polli et al. 2003).

There are many kinds of split-tablets commonly used to treat cardio-vascular diseases, hypertension, diabetic and pediatric complications. Because of different cases of patient and individual variations, with an effort to achieve better clinical effect, tablet splitting is in the service of better matching drug dose to patient's tolerance and in the service of avoiding dose related adverse effects and of improving safety of medications and adherence of patients. In developed country health care provider provide tablet splitting device to split tablet. Inaccurate splitting constitutes both a wrong technique when it is performed without the correct device and a dosing error, and could potentially result in harm for patients. Various methods are used to split tablets: (i) a splitting device (e.g. Pilomat®), (ii) splitting by hand (for scored tablets) or with scissors (for unscored tablets), or (iii) with a kitchen knife. There has been previous research on the impact of tablet splitting on dose accuracy. Reports published so far have concerned splitting devices (Peek et al., 2002; Cook et al., 2003; Boggie et al., 2004), kitchen knives (Cook et al., 2003) and splitting by hand (Babington, 1997; Boggie et al. 2004). In our country patients are not using splitting 
device due to unfamiliarity and cost. So patients split tablet manually by hand or by knife. As a result there are great chances of variation. This may cause serious harm for the patients.

The aim of the study was to quantify the mean deviation from theoretical weight and the mean weight loss, after tablet-splitting with two different, commonly used splitting methods.

\section{MATERIALS AND METHODS}

An experimental design was adopted and the data were collected in July 2010 to September 2010. Three commercially available brands of three different tablets of different sizes and shapes, and which are commonly splitted in homes, were selected for the experiment. Table 1 gives an overview of the characteristics of these tablets.

Table 1: Characteristics of tablets under investigation.

\begin{tabular}{ll}
\hline Drug name & Tablet description \\
\hline Verapamil hydrochloride & Circular shape; White and film coated \\
Metoprolol tartrate & Heart shape; Film coated \\
Atenolol & Circular shape; White color \\
\hline
\end{tabular}

Nevertheless, these tablets are often prescribed in halves or quarters. Two different routine splitting methods were assessed: (i) hand-splitting and (ii) a kitchen knife. No specific splitting guidelines or instructions were given. Per volunteer and per method, the initial weight of ten tablets of each formulation was assessed using an electronic analytical balance (Shimadazu Corporation, Japan), and the mass of each tablet was recorded with an accuracy of $0.1 \mathrm{mg}$. After splitting, each half was individually weighed. For each tablet part, the deviation from the theoretical weight and the weight loss were calculated as follows:

Theoretical weight $=$ weight of the tablet before splitting;

Deviation (\%) from theoretical weight $=$ (weight of the tablet fragment - theoretical weight) /theoretical weight X 100;

Weight loss $=$ weight of the tablet before splitting - sum of all tablet fragments.

\section{Ethical considerations}

The study did not require approval from an ethics committee since we did not collect patient data.

\section{Data analysis}

Percent variation and percent weight loss among the two splitting methods were compared with a one-way ANOVA test.

\section{RESULTS}

Table 2 displays the mean deviation from the theoretical weight for the different tablet parts of each product and the comparison between the two different methods, using a one-way ANOVA test. Overall results are also given. Overall, method 1 provides a significantly lower mean deviation from theoretical weight. The difference between method 1 and method 2 is not statistically significant.

Table 2: Mean and maximum deviation from theoretical weight (\%) for the two evaluated methods $(\mathbf{N}=30)$

\begin{tabular}{cccccccc}
\hline Sample & \multicolumn{3}{c}{ Method 1 } & \multicolumn{3}{c}{ Method 2 } & P value \\
\cline { 2 - 8 } & Mean & SD & Max & Mean & SD & Max & $\begin{array}{c}\text { Method 1 vs } \\
\text { Method 2 }\end{array}$ \\
\hline $\begin{array}{c}\text { Verapamil } \\
\text { hydrochloride }\end{array}$ & 18.94 & 13.01 & 51.07 & 17.52 & 14.38 & 68.01 & 0.819 \\
$\begin{array}{c}\text { Metoprolol tartrate } \\
\text { Atenolol }\end{array}$ & 11.44 & 9.77 & 35.29 & 12.54 & 11.53 & 53.17 & 0.859 \\
\hline
\end{tabular}

Method 1: by hand; Method 2: with a kitchen knife. 
Table 3 displays the number of tablet parts that deviate between $15 \%$ and $25 \%$ from theoretical weight, and the number of tablet parts that deviate more than $25 \%$ from the theoretical weight. While splitting the tablets, some tablet fragments fell on to the floor. These fragments were no longer included in the data processing. As the results show, both methods produced the significant number of tablet parts deviating between $15 \%$ and $25 \%$ from theoretical weight and deviating more than $25 \%$ from theoretical weight.

Table 3: Number of tablet fragments deviating more than $15 \%$ and more than $25 \%$ from the theoretical weight

\begin{tabular}{lcccc}
\hline \multirow{2}{*}{ Sample } & \multicolumn{2}{c}{ Method 1 } & \multicolumn{2}{c}{ Method 2 } \\
\cline { 2 - 5 } & $\begin{array}{c}\text { Deviation } \\
\mathbf{1 5 - 2 5 \%}\end{array}$ & $\begin{array}{c}\text { Deviation } \\
>\mathbf{2 5 \%}\end{array}$ & $\begin{array}{c}\text { Deviation } \\
\mathbf{1 5 - 2 5 \%}\end{array}$ & $\begin{array}{c}\text { Deviation } \\
\text { 25\% }\end{array}$ \\
\hline Verapamil hydrochloride & $6 / 60$ & $12 / 60$ & $4 / 60$ & $1 / 60$ \\
Metoprolol tartrate & $18 / 60$ & $10 / 60$ & $13 / 60^{*}$ & $9 / 60$ \\
Atenolol & $11 / 60$ & $12 / 60$ & $10 / 60$ & $20 / 60^{*}$ \\
\hline
\end{tabular}

Method 1: by hand; Method 2: with a kitchen knife.

${ }^{*}$ Tablet fragments that fell on the floor during splitting were not included.

Not only weight deviations from theoretical weight, but also weight losses were recorded. These results are summarized in Table 4. Method 1 gave the lowest weight loss compared to method 2; the difference between methods 1 and 2 was not statistically significant. However, when pooling the results for the different tablets, method 1 induced statistically significantly less weight loss than the other method.

Table 4: Weight-loss after tablet-splitting (\%), with comparison between the three methods evaluated $(\mathbf{N}=30)$.

\begin{tabular}{cccccccc}
\hline Sample & \multicolumn{3}{c}{ Method 1 } & \multicolumn{3}{c}{ Method 2 } & P value \\
\cline { 2 - 8 } & Mean & SD & Max & Mean & SD & Max & $\begin{array}{c}\text { Method 1 vs } \\
\text { Method 2 }\end{array}$ \\
\hline $\begin{array}{c}\text { Verapamil } \\
\text { hydrochloride }\end{array}$ & -0.10 & 0.32 & -1.55 & -2.25 & 4.74 & -27.40 & $<0.001$ \\
Metoprolol tartrate & -4.80 & 3.34 & -16.11 & -3.40 & 2.76 & -11.91 & 0.030 \\
Atenolol & -1.49 & 0.97 & -5.11 & -4.07 & 2.98 & -11.87 & $<0.001$ \\
\hline
\end{tabular}

Method 1: by hand; Method 2: with a kitchen knife.

\section{DISCUSSION}

\section{Study limitations}

This study had some limitations. It could be argued that we did not compare two distinct methods. However, we wanted to compare two routine methods in order to identify the best possible splitting guidelines for daily practice. Another criticism might be that one volunteer was included. However, we tried to find the splitting variations present even in a single individual. Moreover, we did not investigate the clinical effect of the weight deviations. It seems logical that clinical consequences are small in long-term therapies with agents with long half-lives or high therapeutic indexes. However, there might be some serious clinical consequences when a splitting method is used that produces important dose deviations, for acute therapies, or for drugs with short half-lives or low therapeutic indexes.

\section{Effects of tablet-splitting}

Splitting tablets leads to high variability in both fragment weights and weight losses. This study was undertaken to evaluate the best method for daily tablet-splitting at home. Although some literature is available on this topic, authors have reported their findings in different ways, making comparison difficult (Cook et al., 2003; Mcdevitt et al., 1998; Boggie et al., 2004; Biron et al., 1999; Peek et al., 2002; Teng et al., 2002; Polli et al., 2003; Kayumba et al., 2006). The majority of this literature is a few years old now, whereas the practice remains very alive and still problematic. We 
aimed at providing patients and health care providers with advice for the best splitting technique in daily practice. This means that we needed to search for a technique that is applicable and reliable regardless of the dexterity or training level of the person performing the splitting, and regardless of the tablet's characteristics. We selected tablets with different characteristics to be included in the study. In this way, the findings can be generalized, regardless of the tablet or its brand. The results showed a high variability in weight deviation and weight loss between the two methods. Probably use of a splitting device appeared to be the best method for splitting tablets, since it may be yielded smaller weight deviations and smaller weight losses than using hand or using a kitchen knife.

\section{CONCLUSION}

Tablet-splitting is daily practice in our society. However, not all formulations are suitable for splitting, and even when they are, large dose deviations or weight losses can occur. This could have serious clinical consequences for medications with a narrow therapeutic-toxic range. On the basis of our results, we can warn the people to avoid splitting of tablets and use splitting device when splitting cannot be avoided (i.e. for example when the prescribed dose is not commercially available, or when there is no alternative formulation). As for policy implications, we recommend that manufacturers make it possible to avoid splitting, by introducing a wider range of tablet doses or liquid formulations.

\section{REFERENCES}

Babington MA. (1997), Use of a geriatric formulary in long-term care. Medical Interface. 10(1): 8789.

Biron C, Licznar P, Hansel S, Schved JF. (1999), Oral anticoagulant drugs: do not cut tablets in quarters. Thrombosis and Haemostasis 82:1201.

Boggie DT, Delattre ML, Schaefer MG, Morreale AP, Plowman BK. (2004), Accuracy of splitting unscored valdecoxib tablets. American Journal of Health-System Pharmacy. 61:1482-1483.

Cook TJ, Edwards S, Gyemah C, Shah M, Shah I, Fox T. (2003), Variability in tablet fragment weights when splitting unscored cyclobenzaprine $10 \mathrm{mg}$ tablets. Journal of the American Pharmacy Association. 44:583-586.

Fischbach MS, Gold JL, Lee M, Dergal JM, Litner GM, Rochon PA. (2001), Pill-splitting in a longterm care facility. Canadian Medical Association Journal. 164:785-786.

Kayumba PC, Huyghebaert N, Ntawukuliryayo JD, Vervaet C, Remon JP. (2006), Impact du cassage de comprime's de sulfate de quinine sur l'exactitude de la dose administre'e aux enfants. Le pharmacien d'Afrique. 193:11-16.

Mcdevitt JT, Gurst AH, Chen YS. (1998), Accuracy of tablet splitting. Pharmacotherapy 18:193197.

Peek BT, Al-Achi A, Coombs SJ. (2002), Accuracy of tablet splitting by elderly patients. JAMA. 288:451-452.

Polli JE, Kim S, Martin BR. (2003), Weight uniformity of split tablets required by a Veterans Affairs policy. Journal of Managed Care Pharmacy. 9:401-407.

Teng J, Song C, Williams R, Polli J. (2002), Lack of medication dose uniformity in commonly split tablets. Journal of the American Pharmaceutical Association. 42:195-199.

Van SE, Barends DM, Frijlink HW. (2002), Breaking of scored tablets: a review. European Journal of Pharmaceutics and Biopharmaceutics. 53:139-145. 